\title{
Hypoglycemic effects of Lagenaria siceraria, Cynodon dactylon and Stevia rebaudiana extracts
}

\author{
Dheeraj S. Randive* ${ }^{(\mathbb{D}}$, Mangesh A. Bhutkar, Somnath D. Bhinge, Kiran P. Shejwal, Pranoti D. Patil, Suhas A. Mane \\ Rajarambapu College of Pharmacy, Kasegaon, Dist- Sangli,-415404, State - Maharashtra, India
}

\section{AR T I C L E I N F O}

Article Type:

Original Article

\section{Article History:}

Received: 16 May 2018

Accepted: 10 December 2018

\section{Keywords:}

Hypoglycemic activity

Herbal medicine

Lagenaria siceraria

Cynodon dactylon

Stevia rebaudiana

Amylolysis kinetic

\begin{abstract}
A B S T R A C T
Introduction: The aim of the current analysis was to judge the hypoglycemic action of the phyto-extracts of Lagenaria siceraria, Cynodon dactylon and Stevia rebaudiana using suitable in vitro approaches.

Methods: The hypoglycemic activity of the phyto-material extracts was evaluated by employing various in-vitro methods namely glucose diffusion, amylolysis kinetics and glucose adsorption capacity.

Results: The extracts of L. siceraria, C. dactylon and S. rebaudiana exhibited glucose dialysis retardation indices (GDRI) of 48.14\%, 37.03\% and $29.62 \%$, respectively at 60 minutes which were reduced to $15.78 \%, 10.52 \%$ and $18.42 \%$, respectively at 120 minutes. All the plant extracts used in the study adsorbed glucose and their adsorptions markedly enhanced with increase in sugar concentration.

Conclusion: From the outcome of the assay it can be concluded that the extracts of L. siceraria, C. dactylon and S. rebaudiana have hypoglycemic activity as observed in various in-vitro assays. However, the beneficial actions require to be verified by adopting various in vivo techniques along with clinical trials for their efficient use as potential remedial moiety.
\end{abstract}

Implication for health policy/practice/research/medical education:

Our study may prove to be beneficial to explore the probable mechanism of hypoglycemic action exhibited by the selected plant extracts. The extracts of Lagenaria siceraria, Cynodon dactylon and Stevia rebaudiana were studied for their effects on glucose adsorption capacity, in vitro glucose diffusion, and in-vitro amylolysis kinetics. The results of the present investigation confirmed the hypoglycemic potential of the extracts of L. siceraria, C. dactylon and S. rebaudiana and might be useful in diabetic patients. Please cite this paper as: Randive DS, Bhutkar MA, Bhinge SD, Shejwal KP, Patil PD, Mane SA. Patil, Suhas A. Mane. Hypoglycemic effects of Lagenaria siceraria, Cynodon dactylon and Stevia rebaudiana extracts. J Herbmed Pharmacol. 2018;9(1):51-55. doi: 10.15171/jhp.2019.09.

\section{Introduction}

Diabetes mellitus is a persistent disorder and is a universal chief cause of poor health. It is highlighted by hyperglycemia along with carbohydrate, protein and fat metabolisms. It is also associated with serious complications, including neuropathy, nephropathy, retinopathy, cataract and other health disorders such as Alzheimer's disease and aging $(1,2)$. At present the medicinal remedies of diabetes, along with insulin formulation(s) consist of various oral hypoglycemic namely biguanides, sulfonylureas, thiazolidines, D-phenylalanine moiety, meglitinides and inhibitors of alpha-glucosidase in addition with relevant balanced diet and moderate physical workout. However, no one can be considered as a supreme drug, because of their adverse action and occasionally reduction in action after its use on prolonged treatment (3).
Nowadays, there is an increased interest in herbal drugs and remedies because of the toxic side effects associated with various oral hypoglycemic agents used in the treatment of diabetes mellitus. It was therefore decided to study the hypoglycemic effect of extracts of some indigenous plants known for their antidiabetic activities (1).

Lagenaria siceraria with common name; bottle-gourd, (Cucurbitaceae) is a creeper, with dumbbell pattern fruits. It is widely available throughout India and its flowering top parts and fruits are usually involved in diet as vegetables (4). Moreover, it is used as medicine for its promoting diuresis, tonic and heart tonic properties. Also, different pharmacological activities such as antihepatotoxic, analgesic, anti-inflammatory, lipid lowering, anti-hyperglycemic, immuno-modulatory and anti- 
oxidant activities of the phytoplant extract of $L$. siceraria have already been reported $(5,6)$. Moreover further studies have also been performed on its whole fruits with its seeds. However, the pharmacology of the flowering parts of $L$. siceraria has not been much evaluated. In various parts of the world, the said plant has also been used conventionally as a remedy for metabolic disorders (7-9).

Cynodon dactylon belongs to family Poaceae, is a weed and has been reported to possess an array of medicinal properties such as antimicrobial, antidiabetic, antiinflammatory, antidysentery and other activities (10). The principal components of this plant are flavonoids and sterols (11). It has been traditionally used as an antidiabetic agent in the Ayurveda medicine. (12).

Stevia rebaudiana Bertoni which is a seasonal sweet herb, belongs to Asteraceae, is used as a noncaloric natural sweet in tasting and found in most parts of the universe for its extreme sweetness. The plant is known to produce diterpene glycoside containing stevioside, rebaudioside, etc. Also the leaves are used as a natural low calorie sugar source as a good substitute for table sugar (13). Nowadays, Stevia rebaudiana is commercially cultivated in various Asian countries like India, Pakistan, China, Bangla, Bhutan, Sri Lanka, and Malaysia (14).

The plant-based remedies have already boosted in worldwide because of their assured safety and effectiveness (15). In the forthcoming years, there will be an increased interest in the use of medicinal plants in the developing countries due to their greater safety and lesser side effect(s) as compared to synthetic drugs (16). Thus, the current approach was considered to access the hypoglycemic activity of the selected plant extracts namely L. siceraria, C. dactylon and S. rebaudiana using suitable in vitro approaches.

\section{Materials and Methods}

Chemicals and reagents

Glucose oxidase peroxidase analysis kit was procured from Pathozyme Diagnostics Pvt, Ltd, India. The dialysis tubing (bags) (12000 MW cutoff) were acquired from Himedia Laboratories, 23 Vadhani Industrial Estate, LBS Rd, Mumbai, Maharashtra. The reagents and chemicals used during the project possessed high yield and pure AR grade.

\section{Plant material}

The plant material used in the study was collected from the surrounding region of Kasegaon village, Talukha - Valwa, District - Sangli, (MS), India - 415404. The collected plant material was authenticated by Prof Dr. G.G. Potdar sir, Department of Botany, Yashwantrao Chavan College of Science, Karad, (MS). The authentications number for L. siceraria (DSR/105), C. dactylon (DSR/106) and S. rebaudiana (DSR/107) of the herbarium issued.
Preparation of plant extracts

The leaves of S. rebaudiana (Bert.) and C. dactylon were separately extracted with heated water $\left(70^{\circ} \mathrm{C}\right)$ using a mechanical shaking device ( 24 hours). It was subjected to filtration and finally freeze dried. Fruits of $L$. siceraria were smashed in water and the juice was prepared, filtered and freeze dried. The extracts were properly stored in air tight containers until its use.

Evaluation of in vitro model for hypoglycemic activity of phyto-extracts

Effect of plant extracts on glucose diffusion

One percent w/v samples of plant extracts and $20 \mathrm{mM}$ strength of glucose solutions $(25 \mathrm{~mL})$ were dialyzed by using dialysis tubing converted into bags adjacent to 200 $\mathrm{mL}$ of water (double distilled) at a temperature of $37^{\circ} \mathrm{C}$ using a shaker water bath. At intervals of 30,60, 120 and 180 min the content of remaining glucose in the dialysate was assessed by employing glucose oxidase peroxidase diagnostic analysis kit. Solution without any sample extract served as control. Glucose dialysis retardation indices (GDRI) was calculated as follow (17).

$$
\begin{aligned}
& G D R I= \\
& 100-\frac{\text { Glucose content withaddition of sample }(m g / d L)}{\text { Glucose content of the control }(m g / d L)} \times 100
\end{aligned}
$$

Amylolysis kinetics study of selected plant extracts The plant extracts (1\%), alpha amylase $(0.4 \%)$ and $25 \mathrm{~mL}$ of $4 \%(w / v)$ starch solution were dialyzed by using dialysis tubing against $200 \mathrm{~mL}$ of double distilled water at $37^{\circ} \mathrm{C}$ temperature $(\mathrm{pH} 7.0)$ in a orbital water bath equipped with shaker. At interval of 30, 60, 120 and 180 minutes, the remaining glucose concentration in the dialysate was assessed. A solution without any sample extract served control (18).

Determination of glucose adsorption capacity

Powder extracts $(1 \% \mathrm{w} / \mathrm{v})$ were incorporated to $25 \mathrm{~mL}$ solution of glucose having different strength $(5,10$, 20, 50 and $100 \mathrm{mM}$ ). Then, the resulting liquid was homogenously shaked, thereafter incubated in an orbital shaker with shaking at $37^{\circ} \mathrm{C}$ ( 6 hours) and centrifuged ( $4000 \times \mathrm{g}$ for 20 minutes). The sugar concentration in the supernatant was calculated as follow.

\section{Glucose Bound $(m M)=$}

$$
\frac{G_{1}-G_{6}}{\text { Weight of the sample }} \times \text { Volume of solution }
$$

G1 - Concentration of original solution of glucose

G6 - Glucose concentration after 6 hours

Statistical analysis

All trials were performed in three parallel ways and the 
resulting data were accessed using ANOVA and then compared for Tukey's significant differences. The values were considered significant at $P \leq 0.05$. The graphics were represented using the Graphpad Prism 6 software.

\section{Results}

Effect of plant extracts on glucose diffusion

The results of the selected samples of phyto-extracts for glucose diffusion are shown in Table 1. During analysis, the transport of glucose through membrane of dialysis was determined in intervals of 30 minutes for 180 minutes. The samples showed significant inhibitory action on the mobility of glucose in the surrounding solution on the membrane of dialysis, compared with control.

Effect on in vitro amylosis kinetics

Table 2 shows the extent of glucose diffusion and GDRI observed by the inclusion of phyto-extracts in system of starch- $\alpha$-amylase enzyme fiber. The rate of diffusion of glucose in the samples containing systems decreased with significant effect on the level of $P \leq 0.05$ for each period of time compared to the positive control. In addition, the extent of glucose diffusion was zero for 60 minutes in the plant extract material.

\section{Glucose adsorption capacity}

Figure 1 depicts the adsorption capacity of glucose for the extracts. The adsorption capacity of the phyto-extracts was proportional (directly) to concentration of glucose (M). Greater concentration of glucose was also adsorbed in samples with elevating glucose concentration levels. There were no significant differences among $L$. siceraria, C. dactylon, S. rebaudiana in the adsorption capacity.

\section{Discussion}

Diabetes mellitus is a debilitating hormone disorder in which strict glycemic control and prevention of associated complications are essential (19). According to the review of the literature, it is known that the leaves S. rebaudiana (Bert.), C. dactylon and fruits of Lagenaria siceraria have antidiabetic activities as mentioned earlier in the introduction. Therefore, an effort was undertaken to explore antidiabetic action of $S$. rebaudiana, C. dactylon and fruits of L. siceraria. This is the first attempt to determine the hypoglycemic activity of the leaves $S$. rebaudiana (Bert.), C. dactylon extracts and fruit extract of L. siceraria using different in vitro models, namely glucose uptake in yeast cells, kinetics of amylolysis, glucose adsorption capacity and glucose diffusion. Furthermore, our results revealed a greater adsorption capacity for the leaves extracts of $S$. rebaudiana, $C$. dactylon and fruit extract of $L$. siceraria attributable to their constituents. It has also been previously reported that the insoluble and soluble constituents together with fibers of different origins may contribute to the adsorption of glucose. It has been observed that leaf extracts of $S$. rebaudiana (Bert.) and C. dactylon as well as fruit extract of $L$. siceraria could also effectively adsorb $5 \mathrm{mM}$ glucose concentration, thus declining the mass of glucose accessible for passage through the intestinal lumen (IL) of Gastro Intestinal Tract GIT. The activities of the leaves extracts of $S$. rebaudiana and C. dactylon, and the fruit extract of L. siceraria may be responsible for reducing the post-prandial hyperglycemia. The said observations are in accordance to the findings by (20) for fiber-rich fractions (insoluble) extracted from $A$. carambola.

GDRI remains to be main in-vitro model to forecast the

Table 1. Effect of selected samples on glucose diffusion and glucose dialysis retardation index

\begin{tabular}{lcccc}
\hline & \multicolumn{4}{c}{ Glucose content in dialysate $(\mathbf{m M})$} \\
\cline { 2 - 5 } Particulars & $\mathbf{3 0} \mathbf{~} \mathbf{m i n}$ & $\mathbf{6 0} \mathbf{~ m i n}$ & $\mathbf{9 0} \mathbf{~ m i n}$ & $\mathbf{1 2 0} \mathbf{~ m i n}$ \\
\hline Control & $0.79^{\mathrm{c}} \pm 0.01$ & $1.27^{\mathrm{c}} \pm 0.01$ & $1.77^{\mathrm{c}} \pm 0.01$ & $1.94^{\mathrm{c}} \pm 0.01$ \\
Lagenaria siceraria & $0.51^{\mathrm{a}} \pm 0.01(35.45)$ & $1.06^{\mathrm{a}} \pm 0.01(16.53)$ & $1.53^{\mathrm{a}} \pm 0.01(13.55)$ & $1.68^{\mathrm{a}} \pm 0.01(13.40)$ \\
Cynodon dactylon & $0.48^{\mathrm{b}} \pm 0.01(39.24)$ & $1.14^{\mathrm{b}} \pm 0.01(10.23)$ & $1.63^{\mathrm{b}} \pm 0.01(7.90)$ & $1.81^{\mathrm{b} \pm 0.01(6.70)}$ \\
Stevia rebaudiana & $0.45^{\mathrm{b}} \pm 0.01(43.03)$ & $1.20^{\mathrm{b}} \pm 0.01(7.87)$ & $1.65^{\mathrm{b}} \pm 0.01(6.77)$ & $1.83^{\mathrm{b}} \pm 0.01(5.67)$ \\
\hline
\end{tabular}

The values in parentheses point out the glucose dialysis index (GDRI). Averages $(n=3)$ bearing the letters in depicted table exhibit significant differences compared with control at level $P \leq 0.05$ using two-way ANOVA method.

Table 2. Effect of phyto-extracts on in vitro amylosis kinetics

\begin{tabular}{lcccc}
\hline \multirow{2}{*}{ Plant sample } & \multicolumn{5}{c}{ Glucose content in dialysate $(\mathbf{m M})$} \\
\cline { 2 - 5 } & $\mathbf{3 0} \mathbf{~ m i n}$ & $\mathbf{6 0} \mathbf{~ m i n}$ & $\mathbf{9 0} \mathbf{~ m i n}$ & $\mathbf{1 2 0} \mathbf{m i n}$ \\
\hline Control & 0.0 & $0.27^{\mathrm{c}} \pm 0.01$ & $0.29^{\mathrm{c}} \pm 0.01$ & $0.38^{\mathrm{c}} \pm 0.01$ \\
Lagenaria siceraria & $0.0(100)$ & $0.14^{\mathrm{a}} \pm 0.01(48.14)$ & $0.22^{\mathrm{a}} \pm 0.01(24.13)$ & $0.32^{\mathrm{a}} \pm 0.01(15.78)$ \\
Cynodon dactylon & $0.0(100)$ & $0.17^{\mathrm{b}} \pm 0.01(37.03)$ & $0.24^{\mathrm{b}} \pm 0.01(17.24)$ & $0.34^{\mathrm{b}} \pm 0.01(10.52)$ \\
Stevia rebaudiana & $0.0(100)$ & $0.19^{\mathrm{b}} \pm 0.01(29.62)$ & $0.21^{\mathrm{b}} \pm 0.01(27.58)$ & $0.31^{\mathrm{b}} \pm 0.01(18.42)$ \\
\hline
\end{tabular}

The values in parentheses point out the glucose dialysis index (GDRI). Averages $(n=3)$ bearing the letters in depicted table exhibit significant differences compared with control at level $P \leq 0.05$ using two-way ANOVA method. 


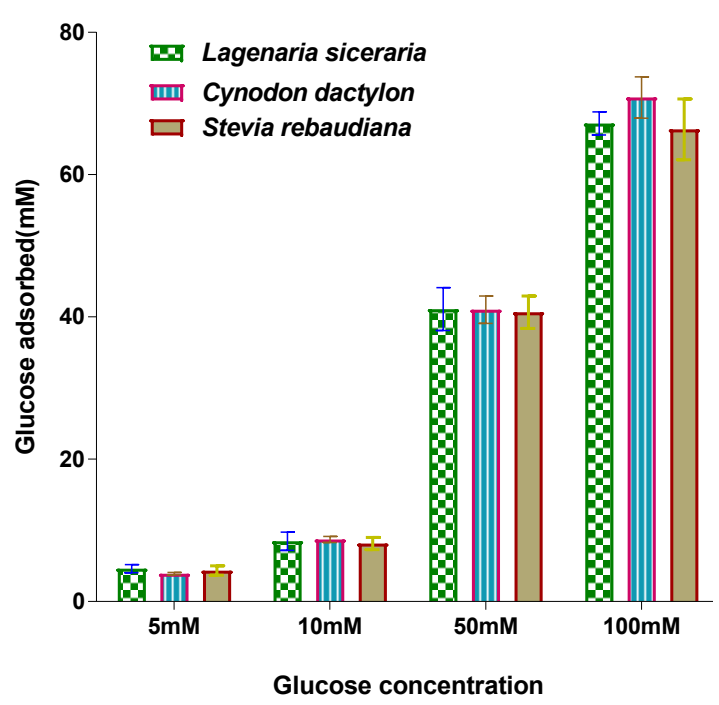

Figure 1. Glucose binding capacity of Lagenaria siceraria, Cynodon dactylon, Stevia rebaudiana at different concentrations of glucose. Values are mean $\pm S D$ of triplicate determinations.

outcome of phytomaterials and its effects on retardation of absorption of glucose in the GIT (21). Higher GDRI is often associated with a greater glucose retardation exhibited by phyto-extracts. In addition, deceleration in glucose diffusion may be attributed to inhibition of an enzyme ( $\alpha$-amylase) by S. rebaudiana (Bert.), C. dactylon and L. siceraria, which limits the conversion of glucose from starch. Various factors can contribute to inhibition of the alpha-amylase enzyme (18). These factors include concentration of fibers, the presence of blockers in the fibers, the coating of the starch and the alpha-amylase enzyme by the fibers present in the phyto-extracts, which reduces the availability of the starch to the alpha-amylase enzyme and the intimate adsorption of the alpha-amylase (digestive) in the fibers, which reduces the activity of amylase $(18,22-24)$. The activity exhibited by the plant extract under study may be attributed to the presence of fibers in the phyto-extracts (18).

\section{Conclusion}

The current investigation revealed hypoglycemic properties of the phyto-extracts of Lagenaria siceraria, Cynodon dactylon, Stevia rebaudiana as evaluated by different in vitro methods. The observed outcomes should be verified by accessing different in vivo techniques along with clinical trials which may credit them to use as therapeutic agents in the treatment of diabetes disorder.

\section{Authors' contributions}

DSR, MAB, KPS and PDP performed the experiment. DSR, $M A B, S D B$ and SAM wrote the manuscript. DSR, MAB, SDB, SAM, KPS and PDP designed and conceptualized the experiment designed. All read and confirmed final version of the manuscript for publication.

\section{Conflict of interests}

The authors declared no competing interests.

\section{Ethical considerations}

Ethical issues have been observed by the authors.

\section{Funding/Support}

This research had no financial support.

\section{References}

1. Bhutkar MA, Bhinge SD, Randive DS, Wadkar GH, Todkar SS. Studies on in-vitro antiglycation potential of some indigenous antidiabetic plants. Glob J Pharm Pharm Sci. 2017;3(5):1-4. doi: 10.19080/GJPPS.2017.03.555624.

2. Sayyed FJ, Wadkar GH. Studies on in-vitro hypoglycemic effects of root bark of Caesalpinia bonducella. Ann Pharm Fr. 2018;76:44-9.

3. Bhutkar MA, Bhinge SD, Randive DS, Wadkar GH. Hypoglycemic effects of Berberis aristata and Tamarindus indica extracts in vitro. Bull Fac Pharm Cairo Univ. 2017;55: 91-94. Doi:10.1016/j.bfopcu.2016.09.001.

4. Saha P, Mazumder UK, Haldar PK, Sen SK, Naskar S. Antihyperglycemic activity of lagenaria siceraria aerial parts on streptozotocin induced diabetes in rats. Diabetologia Croatica. 2011;40(2):49-60.

5. Kirtikar KR, Basu BD. Indian Medicinal Plants. 2nd ed. Dehradun, Uttaranchal, India: Oriental Enterprises; 2003.

6. Shirwaikar A, Sreenivasan KK. Chemical investigation and antihepatotoxic activity of the fruits of Lagenaria siceraria. Indian J Pharm Sci. 1996;58(5):197-202.

7. Duke JA. Handbook of Biologically Active Phytochemicals and Their Activities. Boca Raton, FL: CRC Press, 1992.

8. Palamthodi S, Lele SS. Nutraceutical applications of gourd family vegetables: Benincasa hispida, Lagenaria siceraria and Momordica charantia. Biomed Prev Nutr. 2014;4(1):1521. doi:10.1016/j.bionut.2013.03.004.

9. Sharma D, Rawat I, Goel HC. Antioxidant and prebiotic potential of some cucurbits. Res J Med Plant. 2012;6(7): 500-10.

10. Ramya SS, Vijayanand N, Rathinavel S. Antidiabetic activity of Cynodon dactylon (1.) pers. extracts in alloxan induced rats. Int J Pharm Pharm Sci. 2014; 6(4): 348-52.

11. Rai PK, Jaiswal D, Rai NK, Pandhija S, Rai AK, Watal G. Role of glycemic elements of Cynodon dactylon and Musa paradisiaca in diabetes management. Lasers Med Sci. 2009;24:761-8.

12. Kirtikar KK, Basu BD. Indian Medicinal Plants. 2nd Ed. India: Lali Mohan Publication; 1980. p. 2650.

13. Chalapathi MV, Thimmegowda S. Natural non-calorie sweetener stevia (Stevia rebaudiana Bertoni) a future crop of India. Crop Res Hisar. 1997;14(2):347-50.

14. Thiyagarajan $M$, Venkatachalam P. Large scale in vitro propagation of Stevia rebaudiana (Bert) for commercial application: pharmaceutically important and antidiabetic medicinal herb. Ind Crops Prod. 2012;37:111-7.

15. Randive DS, Adnaik RS, Nalawade PP, Patil AM. Studies on standardization parameters for marketed formulations of draksharishtha. Int J Pharm Biosci. 2014;3(4):397-401.

16. Bhinge SD, Bhutkar MA, Randive DS, et al. Formulation 
development and evaluation of antimicrobial polyherbal gel. Ann Pharm Fr. 2017;75(5):349-58. doi: 10.1016/j. pharma.2017.04.006.

17. Ahmed F, Sairam S, Urooj A. In vitro hypoglycemic effects of selected dietary fibre sources, J Food Sci Technol. 2011;48(3):285-9.

18. Ou S, Kwok KC, Li Y, Fu L. In vitro study of possible role of dietary fiber in lowering postprandial serum glucose. J Agri Food Chem. 2001;49:1026-9.

19. Ojewole JA, Adewunmi CO. Hypoglycemic effect of methanolic extract of Musa paradisiaca (Musaceae) green fruits in normal and diabetic mice. Methods Find Exp Clin Pharmacol. 2003;25(6):453-6.

20. Chau $\mathrm{CF}$, Chen $\mathrm{CH}$, Lin $\mathrm{CY}$. Insoluble fiber-rich fractions derived from Averrhoa carambola: hypoglycemic effects determined by in vitro methods. Lebensm Wiss Technol. 2004;37:331-5.
21. Lopez G, Ros G, Rincon F, Periago MJ, Martinez MC, Ortuno J. Relationship between physical and hydration properties of soluble and insoluble fiber of artichoke. J Agric Food Chem. 1996;44:2773-8.

22. Bhutkar MA, Bhinge SD, Randive DS, Wadkar GH, Todkar SS. Screening of in-vitro hypoglycemic activity of Murraya koenigii and Catharanthus roseus. Ars Pharm. 2018;59(3):17. doi: 10.30827/ars.v59i3.7413.

23. Bhutkar MA, Bhinge SD, Randive DS, Wadkar GH, Todkar SS. In vitro hypoglycemic effects of Caesalpinia bonducella and Myristica fragrans seed extracts. Indian Drugs. 2018;55(1):57-63.

24. Bhinge SD, Bhutkar MA, Randive DS, Wadkar GH, Hasabe T. In vitro hypoglycemic effects of unripe and ripe fruits of Musa sapientum. Brazilian Journal of Pharmaceutical Sciences. 2017;53(4):1-6. doi: 10.1590/ s2175-97902017000400159. 